\title{
Detection of high risk coronary artery disease by thallium imaging
}

\author{
MARTIN J O'HARA, ^ AVIJIT LAHIRI, JOHN R WHITTINGTON, JOHN C W CRAWLEY, \\ EDWARD B RAFTERY
}

From the Department of Cardiology and Division of Clinical Sciences, Northwick Park Hospital and Clinical Research Centre, Harrow, Middlesex

SUMMARY One hundred and three patients who underwent coronary arteriography were studied by thallium imaging and the results analysed by Bayesian principles to assess the usefulness of semiquantitative stress thallium imaging for predicting the presence or absence of multivessel coronary disease. Significant disease was found in 80 patients, of whom 77 had abnormal thallium scans (sensitivity 96\%). Thallium images were normal in 15 of 23 patients with no significant disease (specificity 65\%). Multiple thallium segmental defects were found to be $90 \%$ sensitive and $65 \%$ specific for multivessel coronary artery disease and were present in $80 \%$ of patients with left main stem disease and in $93 \%$ of patients with triple vessel disease. A single thallium defect or normal scan excluded multivessel, left main, and triple vessel disease with $81 \%, 94 \%$, and $91 \%$ predictive accuracy respectively. By Bayesian analysis the predictive accuracy for excluding multivessel disease was $>90 \%$ in patients with a pretest probability of multivessel disease of $\leqslant 40 \%$. Coronary arteriography to exclude multivessel disease is therefore unnecessary in a high proportion of patients with known or suspected coronary artery disease.

The Veterans' Administration' ${ }^{1}$ and European Coronary Surgery ${ }^{2}$ studies have shown that aortocoronary bypass grafting can reduce the mortality in symptomatic patients with left main stem and triple vessel coronary artery disease and also in those with double vessel disease, which includes a long proximal left anterior descending artery lesion. The Coronary Artery Surgery Study confirmed the value of bypass grafting for left main disease even in minimally symptomatic or asymptomatic subjects. ${ }^{3}$ As a result, coronary arteriography is frequently now performed expressly to define the likelihood of a patient's prognosis being improved by coronary surgery. It cannot, however, be performed in all patients with known or suspected coronary artery disease, and non-invasive methods to identify patients at high risk are needed.

Stress myocardial perfusion imaging with thallium-201 is known to be more accurate than exercise electrocardiography for predicting the presence

Requests for reprints to Dr E B Raftery, Department of Cardiology, Northwick Park Hospital, Harrow, Middlesex HAl 3UJ.

^Present address: St. Vincent's Hospital, Dublin 4, Ireland.

Accepted for publication 29 January. 1985 and severity of coronary artery disease ${ }^{4} 5$ and is also reported to predict accurately the presence of multivessel disease after myocardial infarction. ${ }^{67}$

We studied a population with chest pain or with known ischaemic heart disease who were referred for evaluation of the presence or severity of coronary artery disease. We sought to determine whether exercise testing and thallium imaging could predict the presence of multivessel disease, the prognosis for which can be improved by surgical revascularisation. Since the usefulness of any test depends on its predictive accuracy, which in turn depends not only on its sensitivity and specificity but also on the prevalence of disease in the population under study (Bayes's theorem,${ }^{8}$ we estimated the predictive accuracy of thallium imaging for different levels of disease prevalence.

\section{Patients and methods}

The study population comprised 103 patients who underwent stress testing and thallium scanning within 90 days of selective arteriography for the diagnosis or evaluation of coronary disease. There were 87 men 


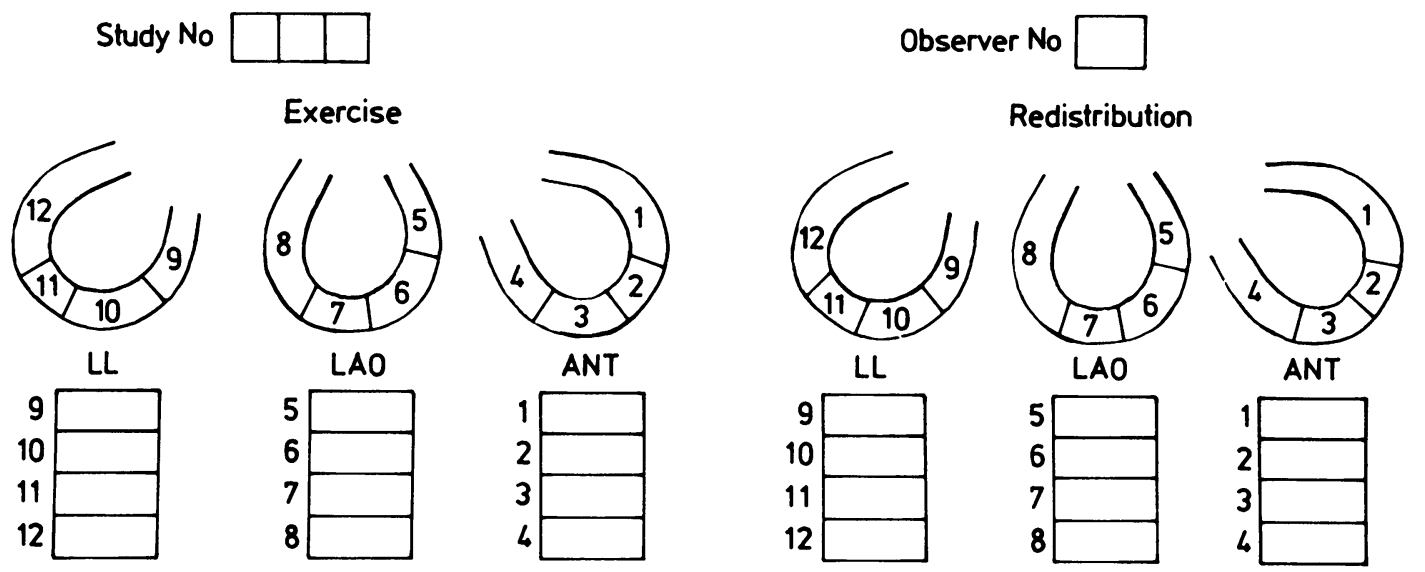

Fig. 1 Diagrammatic representation of the exercise and redistribution myocardial perfusion images as used for reporting the thallium-201 scans.

and 16 women with a mean age of $52 \cdot 1$ (range 35-72) years. Patients with valvar or congenital heart disease, cardiomyopathy, left bundle branch block, or a pacemaker in situ were excluded. Their drug treatment, which was the same at the time of both stress tests, consisted of beta blockers in 20, calcium ion antagonists in 12, long acting nitrates in eight, digoxin in four, and no treatment in 68 .

Fifty four patients had a documented myocardial infarction or a pathological $Q$ wave in the resting electrocardiogram or both. ${ }^{9}$ The remainder had no evidence of previous infarction. Sixty six (64\%, including 35 patients with myocardial infarction) had typical symptoms of angina.

\section{EXERCISE ELECTROCARDIOGRAPHY}

Treadmill tests with a symptomatic end point were carried out using a modified Chung protocol. ${ }^{10}$ Two bipolar leads, CM5 (manubrium sterni negative, V5 position positive) and $\mathrm{CC} 5$ (right V5 position negative, V5 position positive), were used for electrocardiographic monitoring during and for five minutes after exercise. The electrocardiographic signal was analysed by a computer (CASE, Marquette Inc) which measured the ST segment level digitally. The mean ST segment level over a distance equal to one eighth of the RR interval (or $80 \mathrm{~ms}$ whichever was the less), the ST bar, was measured every 12 seconds and the digital values stored for recall at the end of the test. An abnormal ST segment response was defined as ST bar depression of $0.1 \mathrm{mV}$ absolute and relative to the resting value.

\section{THALLIUM SCINTIGRAPHY}

A treadmill exercise protocol identical to that used for exercise electrocardiography was used for stress myocardial scintigraphy. At peak exercise $74 \mathrm{MBq}$ of thallium-201 was injected via an indwelling venous cannula. Exercise was then continued for a further 30 seconds at a reduced workload. Within 5-10 minutes of the end of exercise imaging was performed using a Pho-Gamma II (Searle) scintillation camera with a high resolution collimator and a $20 \%$ window about the $80 \mathrm{KeV}$ photo peak of thallium-201. Three hundred thousand counts were acquired in the anterior, $45^{\circ}$ left anterior oblique, and left lateral

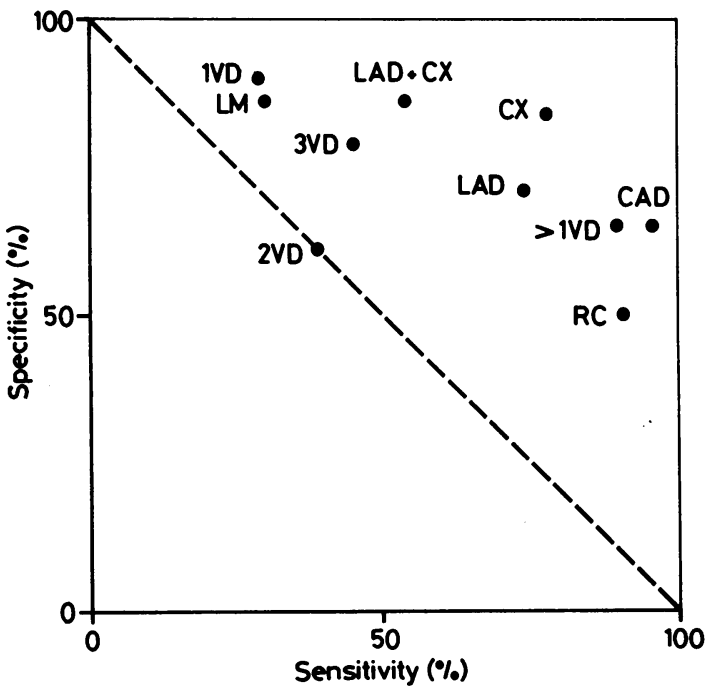

Fig. 2 Relative values of serisitivity and specificity for the prediction of the presence, location, and number of diseased vessels by segmental analysis of thallium-201 images. IVD, one vessel disease, $2 V D$, two vessel disease; $>I V D$, multivessel disease; $L M$, left main; $L A D$, left anterior descending; $C X$, circumflex; $C A D$, coronary artery disease; $R C$, right coronary. 
views. A lead sheet shielded the camera from activity due to the abdominal uptake of thallium. Redistribution scans were obtained in the same views 3-4 hours after exercise. The data were stored on hard disk in a $64 \times 64$ matrix and were analysed by a Gamma 11 computer (Digital Equipment Corp).

The exercise and redistribution scans were analysed semiquantitatively from the images displayed on the cathode ray tube by two experienced observers who were unaware of the results of other investigations. The images were interpolated to a $128 \times 128$ matrix, $30 \%$ of the lower threshold was subtracted, and nine point smoothing was carried out. A 15 point colour scale was used to identify areas with $25 \%$ count reduction relative to the myocardial area of maximal count density, and these areas were defined as abnormal. To
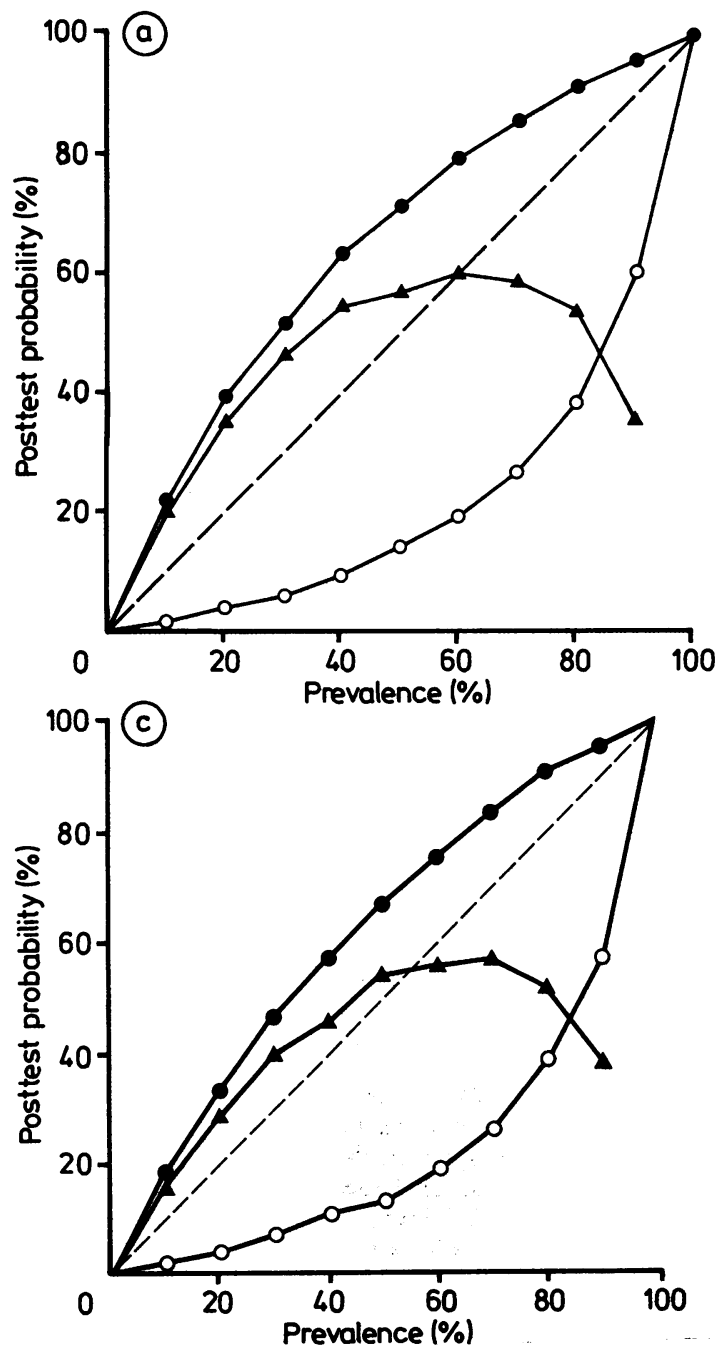

detect redistribution of thallium the early and late scans were compared side by side.

To identify the location of perfusion defects the thallium images were divided into 12 segments and scored as shown in Fig. 1. The following myocardial segments were considered to be supplied by the individual major coronary vessels: left anterior descending, segments $1,8,12$; circumflex, 5, 6, 9; and right coronary, 3, 4, 7, 10 (Fig. 1). Arteas 2 and 11 were considered non-specific for any coronary vessel and the scans were reported so as to arrive at the least number of vessels that could account for the observed defects.

\section{CORONARY ARTERIOGRAPHY}

The right and left coronary arteries were selectively

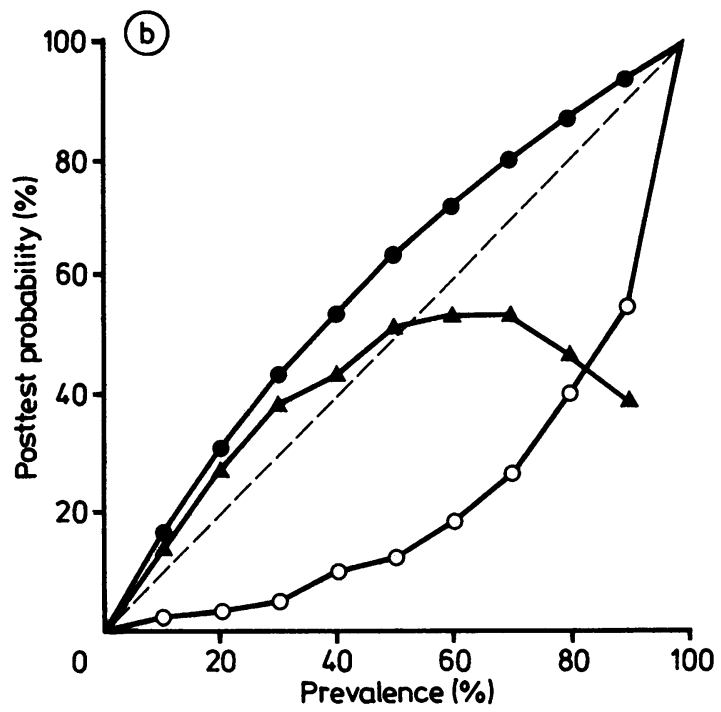

Fig. 3 Bayesian analysis using the sensitivity and specificity derived from all 103 patients to estimate the post-test probability of (a) multivessel disease, (b) triple vessel disease, and (c) left anterior descending and circumflex artery stenosis (including left main stem disease) predicted by multiple thallivon vascular territory defects in populations with different pretest probabilities (prevalence) of such disease - represents the probability of disease after a positive test - that is, $>1$ thalliven vascular territory defect; $\bigcirc-O$ represents the probability after a negative test - that is, nomal thallizon image or single thallitom segmental defect; $\Delta-\Delta$ represents the difference of post-test probability between the other two curves (note that the circles and triangles represent arbitrary probability values not actual data points); -. - represents a test with no discriminative ability and the vertical distance of the curves from this straight line is an index of the test's discriminative ability. 
Table 1 Results of coronary arteriography in 103 patients. Figures are numbers of patients

\begin{tabular}{|c|c|c|}
\hline & \multicolumn{2}{|c|}{ Myocardial infarction } \\
\hline & $\begin{array}{l}\text { Absent } \\
(n=49)\end{array}$ & $\begin{array}{l}\text { Present } \\
(n=54)\end{array}$ \\
\hline $\begin{array}{l}\text { No significant disease } \\
\text { Luminal stenosis }>70 \%\end{array}$ & 23 & $\begin{array}{r}0 \\
54\end{array}$ \\
\hline No of diseased vessels: & & \\
\hline 1 & 8 & 9 \\
\hline 2 & 7 & 16 \\
\hline$\stackrel{3}{3}$ & 11 & 29 \\
\hline $\begin{array}{l}\text { Location: } \\
\text { Left anterior descending artery }\end{array}$ & & \\
\hline $\begin{array}{l}\text { Left anterior descending artery } \\
\text { Circumflex artery }\end{array}$ & $\begin{array}{l}22 \\
17\end{array}$ & $\begin{array}{l}45 \\
44\end{array}$ \\
\hline Right coronary artery & 16 & 37 \\
\hline $\begin{array}{l}\text { Left main coronary artery and three } \\
\text { vessel disease }\end{array}$ & 1 & 8 \\
\hline $\begin{array}{l}\text { Left main coronary artery alone } \\
\text { Left anterior descending and circumflex } \\
\text { arteries }\end{array}$ & $\begin{array}{r}0 \\
15\end{array}$ & 29 \\
\hline
\end{tabular}

injected by Judkins's or Sones's technique. Significant disease was defined as $\geqslant 70 \%$ stenosis of a major coronary vessel or $\geqslant 50 \%$ stenosis in the case of the left main coronary artery. When significant disease was found in a dominant right coronary artery, the circumflex artery being rudimentary, or vice versa, two vessel disease was considered to be present. The arteriograms were reported independently by a radiologist and a cardiologist who conferred in cases of disagreement. The results of thallium imaging did not influence the decision to perform coronary arteriography.

\section{ANALYSIS}

The findings of thallium myocardial scintigraphy and stress electrocardiography were compared with the results of coronary angiography to determine the ability of the non-invasive tests to detect and identify the location of significant coronary artery disease. Sensitivity was defined as (true positives)/(true positives + false negatives) and specificity as (true negatives)/(true negatives + false positives). Positive predictive accuracy is the proportion of positive tests and negative predictive accuracy the proportion of negative tests that are correct.

The values of sensitivity and specificity within groups were compared by means of McNemar's matched pairs test. Between group comparisons of sensitivity, specificity, and predictive accuracy were performed by the probability of a proportion. Values of $p<0.05$ were considered to be significant.

\section{BAYESIAN ANALYSIS}

To be of practical use to clinicians the probability of an individual patient having disease in the event of a positive and in the event of a negative test must be known. According to Bayes's theorem this past-test probability of disease depends on the pretest probability of disease as well as on the test's sensitivity and specificity. ${ }^{8}$ The data from the Coronary Artery Surgery Study, ${ }^{11}$ or other sources, ${ }^{8}$ can be used to estimate the pretest probability of disease in a given patient if the age, sex, and type of symptoms are known. It was assumed that the test's sensitivity and specificity were independent of disease prevalence. ${ }^{8}$ The post-test probability of disease can then be derived from the following equations:

(a) $\mathrm{P}(+)=\frac{\mathrm{Pre}}{\mathrm{Pre}+(1-\mathrm{Pre}) / \mathrm{L}}$ where $\mathrm{P}(+)$ is the post-test probability of disease when the test is positive; Pre, the pretest probability of disease; and L, the likelihood ratio (sensitivity/(1-specificity)).

(b) $\mathrm{P}(-)=\frac{\text { Pre }}{\text { Pre }+(1-\text { Pre }) \times \mathrm{U}}$ where $\mathrm{P}(-)$ is the post-test probability of disease when the test is negative; and $\mathrm{U}$, the unlikelihood ratio (specificity/(1-sensitivity)).

Using the values of sensitivity and specificity from this study $\mathrm{P}(+)$ and $\mathrm{P}(-)$ were calculated and plotted on a vertical axis with the pretest probability, range $0-100 \%$, on the horizontal axis and the curves so obtained are shown in Fig. 2.

\section{Results}

\section{CORONARY ARTERIOGRAPHY}

Significant coronary narrowing was found in all the 54 patients with previous myocardial infarction and in 26 (53\%) of those with no evidence of previous infarction. Six patients had luminal stenoses of $<70 \%$-five in three vessels and one in a single vessel-and 17 patients had no abnormality of the major coronary vessels. Table 1 shows the results of arteriography.

\section{THALLIUM SCINTIGRAPHY}

Figure 3 shows the sensitivity and specificity of thallium imaging for predicting the presence, location, and extent of coronary artery disease. With an ideal test for coronary disease all points would lie in the upper right hand corner of the graph. Of the 80 patients with significant coronary disease, 77 had at least one myocardial area of diminished (fixed or reversible) thallium uptake (sensitivity $96 \%$ ). The thallium images were abnormal in all 54 patients with previous myocardial infarction: 17 had fixed defects only, 29 had both fixed and reversible defects, and eight had reversible defects only. The thallium scintigrams were abnormal in eight of the 23 patients with no significant coronary disease (specificity $65 \%$ ) (Table 2), none of whom had a previous myocardial infarction. Five of these had normal coronary arteries and three had non-significant disease. In patients with no previous infarction thallium imaging had a sensitivity of $88 \%$, a specificity of $65 \%$, a positive predic- 
tive accuracy of $74 \%$, and a negative predictive accuracy of $83 \%$.

Redistribution of thallium between the early and late scans was seen in 55 patients with coronary disease. The proportion of those with infarction (37 of 54) and with no infarction (18 of 26) was the same (69\%). Redistribution was seen in only three patients (with normal coronaries) out of 23 with no significant arteriographic disease (specificity $87 \%$ ).

\section{Prediction of individual coronary vessel disease}

The sensitivity of segmental thallium uptake defects for detecting individual vessel disease was $91 \%$ for disease of the right coronary artery compared with $77 \%$ for the left anterior descending artery $(p<0.05)$ and $76 \%$ for the circumflex ( $\mathrm{p}<0.05$ vs right coronary; NS vs left anterior descending) (Fig. 3). The specificity of segmental thallium defects was $88 \%$ for circumflex disease, $69 \%$ for the left anterior descending $(p<0.05)$, and $50 \%$ for the right coronary $(p<0.01$ $v s$ circumflex). The specificity of left anterior descending and right coronary defects did not differ significantly.

In patients with single vessel disease the values of sensitivity and specificity for each coronary vessel were: left anterior descending, 10/11 $(91 \%)$ and 1/6 (17\%); circumflex, $1 / 2(50 \%)$ and $10 / 15(67 \%)$; and right coronary, $3 / 4(75 \%)$ and $3 / 13(23 \%)$ respectively.

\section{Prediction of the number of diseased vessels}

Table 2 shows the numbers of patients having one, two, or three thallium vascular segmental defects and their arteriographic classification. A minority of patients in each arteriographic group was correctly classified by thallium imaging. As plotted in Fig. 3, the specificity of thallium prediction for one and three vessel disease was high, but for two vessel disease it had no useful predictive ability. Eight of the 10 patients with single vessel disease but multiple thallium segmental defects had $<70 \%$ stenoses in at least one other major coronary vessel.

\section{Left main stem disease}

Nine of the 10 patients with left main coronary artery disease had triple vessel disease in addition. Three of these were correctly identified by thallium defects in three coronary vessel regions (sensitivity $30 \%$, Fig. 3 ). A further three had defects in the territories of the left anterior descending and right coronary: one had circumflex and right coronary defects, one an isolated right coronary defect, and one a normal thallium scan. One patient with previous infarction had isolated left main stem disease and had thallium defects in the territories of the left anterior descending and right coronary arteries.

Fifty four patients had left main coronary artery disease or combined disease in the left anterior descending and circumflex arteries. Twenty nine of these had thallium uptake defects in the corresponding myocardial segments (sensitivity 54\%). The specificity of combined left anterior descending and circumflex defects was $42 / 49$ (86\%). The positive and negative predictive accuracies were $81 \%$ and $63 \%$ respectively.

\section{Multiple segmental thallium defects and multivessel disease}

Using the criterion of thallium defects in more than one vascular territory the sensitivity for detecting high risk coronary disease was high, but the specificity was moderate (Table 3). Of 18 patients with normal thallium images, only one had multivessel (left main stem and triple vessel) disease-that is, the predictive accuracy of a normal scan for the absence of multivessel disease was $17 / 18$ (94\%).

\section{EXERCISE ELECTROCARDIOGRAPHY}

The sensitivity and specificity of $0.1 \mathrm{mV}$ ST segment depression for detecting coronary artery disease in patients with no previous infarction were $18 / 26(69 \%)$ and $15 / 23(65 \%)$ respectively (both NS vs thallium imaging). The sensitivity of ST segment depression for the detection of multivessel disease was $62 \%$, for three vessel disease $60 \%$, and for left main disease $50 \%$. Thus in this study two lead stress testing was no more sensitive for detecting serious multivessel disease than for detecting coronary artery disease in general.

Table 2 Prediction of number of diseased coronary vessels by thallium imaging. Figures are numbers of patients

\begin{tabular}{|c|c|c|c|c|c|}
\hline & \multicolumn{4}{|c|}{ No of diseased vessels by thallium imaging } & \multirow[t]{2}{*}{ Total } \\
\hline & 0 & 1 & 2 & 3 & \\
\hline $\begin{array}{c}\text { No of } \\
0^{*} \\
1 \\
2 \\
3 \\
\text { Total }\end{array}$ & $\begin{array}{c}15 t \\
2 \\
0 \\
1 \\
18\end{array}$ & $\begin{array}{r}4 \\
5 t \\
3 \\
2 \\
14\end{array}$ & $\begin{array}{c}4 \\
8 \\
9 \\
19 \\
40\end{array}$ & $\begin{array}{c}0 \\
2 \\
11 \\
18+ \\
31\end{array}$ & $\begin{array}{l}23 \\
17 \\
23 \\
40\end{array}$ \\
\hline
\end{tabular}

^Includes six patients with non-significant disease ( $<70 \%$ luminal stenosis).

$\dagger$ Number of patients correctly classified by thallium-201 imaging. 
Table 3 Multivessel coronary disease prediction by thallium defects in more than one vessel's territory $(n=103)$. Figures are numbers (\%)

\begin{tabular}{lcccc}
\hline & Sensitivity & Specificity & $\begin{array}{l}\text { Positive predictive } \\
\text { accuracy }\end{array}$ & $\begin{array}{l}\text { Negative predictive } \\
\text { accuracy }\end{array}$ \\
\hline $\begin{array}{l}\text { Left main disease } \\
\text { Left main disease or left anterior }\end{array}$ & $8 / 10(80)$ & $30 / 93(32)$ & $8 / 71(11)$ & $30 / 32(94)$ \\
descending and circumflex artery disease & $37 / 40(93)$ & $27 / 49(55)$ & $49 / 71(69)$ & $27 / 32(84)$ \\
$\begin{array}{l}\text { Three vessel disease } \\
\text { More than 1 vessel disease }\end{array}$ & $57 / 63(90)$ & $29 / 63(46)$ & $37 / 71(55)$ & $29 / 32(91)$ \\
\hline
\end{tabular}

Using the criterion of either an abnormal thallium image or an abnormal ST segment exercise response for a positive test the sensitivity for the detection of coronary artery disease was $88 \%$ (NS vs thallium and vs ST alone) but the specificity was $35 \%(\mathrm{p}<0.05)$. Defining an abnormal test as one in which both the thallium scan and the ST segment exercise response were abnormal gave a lower sensitivity $(62 \%, p<0.05$, vs thallium alone), but the specificity increased to $96 \%$ ( $p<0.05 v s$ thallium alone). Thus combined analysis yielded an improvement in specificity only at the cost of a loss of sensitivity, and in this study there was no significant improvement of predictive accuracy.

\section{BAYESIAN ANALYSIS}

When the criterion of multiple segmental thallium defects was used to construct curves relating pretest and posttest probabilities of high risk coronary artery disease (Fig. 2) a relatively low increment of probability of disease with a positive test was noted at all disease prevalence levels, which is in keeping with the low specificity. The value of a negative test for excluding multivessel disease was high owing to the test's high sensitivity. In populations with a pretest probability of high risk disease of $\leqslant 30 \%$ a negative test reduced the post-test probability to $\leqslant 5 \%$ for multivessel, left main, and triple vessel disease.

\section{Discussion}

While the value of aortocoronary bypass surgery for the relief of intractable angina is not disputed its effect on life expectancy in patients with coronary artery disease is more controversial. ${ }^{12}$ The Veterans Administration $^{1}$ and European Coronary Surgery ${ }^{2}$ studies have reported an improvement in prognosis in certain categories of patients treated surgically compared with controls. These categories were defined in terms of coronary anatomy, and, therefore, although we have to rely on the results of these two studies when deciding for or against coronary surgery, the non-invasive tests used to detect coronary artery disease must be compared with coronary arteriography. Exact agreement between the results of thallium imaging or stress electrocardiography and coronary arteriograpy is not to be expected since the noninvasive methods give functional as opposed to anatomical information about the myocardium. Both non-invasive methods probably have a prognostic value independent of the arteriographic findings. ${ }^{13-15}$ We have evaluated the accuracy of planar thallium imaging for the detection or exclusion of multivessel disease, for which coronary bypass surgery is thought to improve the prognosis. We sought to determine whether coronary arteriography can be avoided in some patients and whether the addition of ST segment analysis can improve the accuracy of thallium imaging alone.

Stress thallium-201 scintigraphy has been shown to be more accurate than stress electrocardiography for detecting obstructive coronary artery disease..$^{45} \mathrm{We}$ found semiquantitative thallium imaging to be highly sensitive $\mathbf{8 8 \%}$ in patients with no previous infarction, $96 \%$ overall), a value which corresponds with the $82 \%$ average of studies cited by Okada $e t a l,{ }^{4}$ which used subjective visual interpretation, and is comparable to the sensitivity reported with quantitative thallium image analysis. 1617 The sensitivity of perfusion scintigraphy in this study was probably enhanced by the definition of significant coronary disease as $\geqslant 70 \%$ luminal stenosis. Moderate $(50-70 \%)$ stenoses are more frequently associated with a normal perfusion pattern. ${ }^{17}$ Furthermore, there was a high prevalence of multivessel disease-63 of $80(79 \%)$ patients-for which thallium imaging is more sensitive than for less extensive disease. ${ }^{18}$

The specificity of thallium imaging in this series $(65 \%)$ is lower than in most reported studies. The choice of $70 \%$ stenosis as significant may have contributed to this. Three of the six patients who had coronary narrowing of $<70 \%$ luminal diameter had abnormal thallium scans, which may indicate that these lesions were haemodynamically significant. Angiography frequently underestimates the true extent and severity of coronary disease and, in the range $25-70 \%$ stenosis, is subject to considerable interobserver variability. 1920

We found that disease of the right coronary artery was most readily detected $(91 \%)$ followed by left anterior descending (77\%) and circumflex disease (76\%). Massie et al found similar values of sensitivity 
and concluded that the severity of vessel stenosis was the most important factor determining the sensitivity of thallium imaging for detecting individual vessel disease. ${ }^{21}$ Maddahi and colleagues report that quantitative thallium analysis affords a small, but important, improvement in identifying diseased vessels, which may be valuable in evaluating the functional significance of coronary stensosis in the $50-70 \%$ range. ${ }^{17}$ As noted by others, thallium imaging was a poor predictor of the number of diseased vessels, ${ }^{21} 22$ and this may be due to the variability of coronary vessel dominance, especially in the inferior wall of the left ventricle.

The value of segmental analysis of thallium uptake for the prediction of multivessel coronary artery disease has been questioned. ${ }^{21-25}$ Lenaers et al reported that $52 \%$ of patients with scintigrams suggesting single vessel disease had multivessel disease. ${ }^{23} \mathrm{McKil}-$ lop et al also concluded that semiquantitative thallium imaging could not help in identifying patients with high risk coronary disease who might benefit from surgery. ${ }^{24}$ Maddahi et al reported that a higher proportion of coronary lesions in patients with triple vessel disease was detected by quantitative thallium imaging than by visual interpretation ( $83 \%$ vs $53 \%$ ). ${ }^{17}$ Gewirtz et al also reported an improved lesion detection rate with quantitative analysis, but the sensitivity for detecting patients with triple vessel disease was increased only from $33 \%$ to $48 \% .{ }^{26}$

The sensitivity and specificity for detecting left main, triple vessel, and multivessel disease by corresponding segmental thallium defects in our study (Fig. 3) do not differ appreciably from those reported by others. Sensitivity for detecting high risk coronary artery disease was increased by using the criterion of multiple segmental defects. This results in a loss of specificity, but may be justified on the basis of the variability of predominance of the right and left coronary circulations and by our knowledge of the prognostic significance of multiple perfusion defects. ${ }^{14}$ is

The finding of multiple defects in 10 of our patients with single vessel disease implies that the stenoses of $<70 \%$ in other vessels (in eight patients) were significant or that extensive myocardium was jeopardised by disease in one major coronary vessel (in two patients). Compared with a single defect or normal thallium scan, even in patients with angiographic single vessel disease, multiple thallium defects predict future cardiac events, both in patients presenting with chest pain ${ }^{14}$ and after myocardial infarction. ${ }^{15}$

In this study three patients with triple vessel disease had either a normal thallium scan (one patient) or only one segmental defect (two patients). Diffusely decreased myocardial perfusion as occurs with severe three vessel disease can result in an image with homogeneously decreased thallium uptake but no identifiable defects. ${ }^{23} 24$ Similarly, the finding of only one segmental defect in two patients with triple vessel disease may imply that only the area of greatest hypoperfusion was identified or that collaterals were preserving perfusion to other regions.

When multivessel disease coexists with myocardial infarction thallium imaging may be used to assess the presence of reversible ischaemia in the non-infarcted areas. Revascularisation of jeopardised myocardium may be very important in patients with previous infarction since preservation of left ventricular function may benefit their prognosis. ${ }^{27}$

According to Bayes's theorem the predictive value of an inaccurate test depends on the prevalence (or pretest likelihood) of disease in the population under study as well as on the test's sensitivity and specificity, and the latter were assumed in this study to be independent of disease prevalence. This assumption may be questioned, as thallium imaging might be more sensitive in a population with a high prevalence of coronary artery, and thus multivessel, disease. ${ }^{18}$ The utility of our Bayesian approach can, however, be judged only by testing it prospectively in a new population of patients. When Greenberg and colleagues evaluated exercise testing in this way they found Bayesian analysis to be equally as accurate as discriminant function analysis ${ }^{28}$ (which does not assume independence of test sensitivity and disease prevalence).

Inaccurate tests are of limited value in patients with a pretest likelihood of disease $>90 \%$ or $<10 \%$. When the values of sensitivity and specificity obtained in this study were used to calculate the post-test probability of multivessel disease in populations with different pretest probabilities, we found that a negative test excluded multivessel coronary artery disease with $>90 \%$ probability if the pretest probability of multivessel disease was $<40 \%$ (see Fig. 2). Data from the Coronary Artery Surgery Study indicated that approximately half the patients with no previous infarction undergoing coronary arteriography fell into this category. 1 The pretest probability of left main or triple vessel disease was less than $40 \%$ in over $70 \%$ of patients undergoing coronary arteriography in this study. " Thus the need for arteriography as a guide to prognosis can be avoided in a high proportion of patients presenting for investigation of chest pain.

We used two bipolar leads, CM5 and CC5, a combination reported to be as sensitive and specific as multiple lead systems for detecting coronary artery disease. ${ }^{2 y}$ In this study, however, the sensitivity and specificity of ST segment displacement during exercise were only $69 \%$ and $65 \%$ respectively in patients without previous myocardial infarction. The addition of ST segment analysis did not improve the predictive accuracy of thallium imaging. 
The finding that in patients with a high prevalence of multivessel coronary artery disease high risk disease can be excluded with confidence by means of stress thallium imaging suggests that in a less selected population a normal thallium scan or single perfusion defect indicates the absence of multivessel disease and renders coronary angiography for prognostic purposes unnecessary.

\section{References}

1 Takaro T, Hultgren HN, Lipton MJ, Detre K. The VA co-operative randomized study of surgery for coronary arterial occlusive disease. II Subgroup with significant left main lesions. Circulation 1976; 54 (suppl III): 10717.

2 European Coronary Surgery Study Group. Long-term results of prospective randomised study of coronary artery bypass surgery in stable angina pectoris. Lancet 1982; ii: 1173-80.

3 CASS principal investigators and their associates. Coronary artery surgery study (CASS): a randomized trial of coronary artery bypass surgery: survival data. Circulation 1983; 68: 939-50.

4 Okada RD, Boucher CA, Strauss HW, Pohost GM. Exercise radionuclide imaging approaches to coronary artery disease. Am $\mathcal{F}$ Cardiol 1980; 46: 1188-204.

5 Bodenheimer MM, Banka VS, Fooshee CM, Helfant RH. Comparative sensitivity of the exercise electrocardiogram, thallium imaging and stress radionuclide angiography to detect the presence and severity of coronary heart disease. Circulation 1979; 60: 1270-8.

6 Dunn RF, Freedman B, Bailey IK, Uren R, Kelly DT. Noninvasive prediction of multivessel disease after myocardial infarction. Circulation 1980; 62: 726-34.

7 Gibson RS, Taylor GT, Watson DD, et al. Predicting the extent and location of coronary artery disease during the early postinfarction period by quantitative thallium-201 scintigraphy. Am $\mathcal{F}$ Cardiol 1981; 47: 1010-9.

8 Diamond GA, Forrester JS. Analysis of probability as an aid in the clinical diagnosis of coronary-artery disease. $N$ Engl f Med 1979; 300: 1350-8.

9 Classification of the electrocardiogram "Minnesota Code". In: Rose GA, Blackburn H, eds. Cardiovascular survey methods. Geneva: World Health Organisation (Monograph Series, No. 56), 1968.

10 O'Hara MJ, BalaSubramanian V, Davies AB, Raftery EB. Changes of $Q$ wave amplitude during exercise for the prediction of coronary artery disease. Int $\mathcal{F}$ Cardiol 1984; 6: $35-45$.

11 Chaitman BR, Bourassa MG, Davis K, et al. Angiographic prevalence of high-risk coronary artery disease in patient subsets (CASS). Circulation 1981; 64: 360-7.

12 Braunwald E. Effects of coronary-artery bypass grafting on survival. Implications of the randomized coronary artery surgery study. $N$ Engl $\mathrm{f}$ Med 1983; 309: 1181-4.

13 Gohlke H, Samek L, Betz P, Roskamm H. Exercise testing provides additional prognostic information in angiographically defined subgroups of patients with coronary artery disease. Circulation 1983; 68: 979-85.

14 Brown KA, Boucher CA, Okada RD, et al. Prognostic value of exercise thallium-201 imaging in patients presenting for evaluation of chest pain. $\mathcal{F}$ Am Coll Cardiol 1983; 1: 994-1001.

15 Gibson RS, Watson DD, Craddock GB, et al. Prediction of cardiac events after uncomplicated myocardial infarction: a prospective study comparing predischarge exercise thallium-201 scintigraphy and coronary angiography. Circulation 1983; 68: 321-36.

16 Burow RD, Pond M, Schafer AW, Becker L. "Circumferential profiles": a new method for computer analysis of thallium-201 myocardial perfusion images. $\mathcal{f}$ Nucl Med 1979; 20: 771-7.

17 Maddahi J, Garcia EV, Berman DS, Waxman A, Swan HJC, Forrester J. Improved non-invasive assessment of coronary artery disease by quantitative analysis of regional stress myocardial distribution and washout of thallium-201. Circulation 1981; 64: 924-35.

18 Dash H, Massie BM, Botvinick EH, Brundage BH. The noninvasive identification of left main and three-vessel coronary artery disease by myocardial stress perfusion scintigraphy and treadmill exercise electrocardiography. Circulation 1979; 60: 276-84.

19 Abrams HL. Coronary arteriography: pathologic and prognostic implications. AfR 1982; 139: 1-18.

20 De Rouen TA, Murray JA, Owen W. Variability in the analysis of coronary arteriograms. Circulation 1977; 55: 324-8.

21 Massie BM, Botvinick EH, Brundage BH. Correlation of thallium-201 scintigrams with coronary anatomy: factors affecting region by region sensitivity. Am $\mathcal{F}$ Cardiol 1979; 44: 616-22.

22 Rigo P, Bailey IK, Griffith LSC, et al: Value and limitations of segmental analysis of stress thallium myocardial imaging for localization of coronary artery disease. Circulation 1980; 61: 973-81.

23 Lenaers A, Block P, van Thiel E, et al. Segmental analysis of TI-201 stress myocardial scintigraphy. 7 Nucl Med 1977; 18: 509-16.

24 McKillop JH, Murray RG, Turner JG, Bessent RG, Lorimer AR, Greig WR. Can the extent of coronary artery disease be predicted from thallium-201 myocardial images? F Nucl Med 1979; 20: 715-9.

25 Berger HJ, Zaret BL. Nuclear cardiology (first of two parts). $N$ Engl f Med 1981; 305: 799-807.

26 Gewirtz H, Paladino W, Sullivan M, Most AS. Value and limitations of myocardial thallium washout rate in the noninvasive diagnosis of patients with triple-vessel coronary artery disease. Am Heart $\mathcal{F}$ 1983; 106: 681-6.

27 Alderman EL, Fisher LD, Litwin P, et al. Results of coronary artery surgery in patients with poor left ventricular function (CASS). Circulation 1983; 68: 785-95.

28 Greenberg PS, Ellestad MH, Clover RC. Comparison of the multivariate analysis and CADENZA systems for determination of the probability of coronary artery disease. Am f Cardiol 1984; 53: 493-6.

29 Chaitman BR, Bourassa MG, Wagniart P, Corbara F, Ferguson RJ. Improved efficiency of treadmill exercise testing using a multiple lead ECG system and basic hemodynamic exercise response. Circulation 1978; 57: 71-9. 